\title{
Scientific Literacy in Second Chance Schools: Training Science Teachers to Design Context-based Curricula
}

\author{
Spyros Kollas*, Krystallia Halkia \\ School of Education, National and Kapodistrian University of Athens, Greece
}

Received December 13, 2019; Revised August 7, 2020; Accepted August 25, 2020

\section{Cite This Paper in the following Citation Styles}

(a): [1] Spyros Kollas, Krystallia Halkia , "Scientific Literacy in Second Chance Schools: Training Science Teachers to Design Context-based Curricula," Universal Journal of Educational Research, Vol. 8, No. 10, pp. 4877 - 4890, 2020. DOI: 10.13189/ujer.2020.081060.

(b): Spyros Kollas, Krystallia Halkia (2020). Scientific Literacy in Second Chance Schools: Training Science Teachers to Design Context-based Curricula. Universal Journal of Educational Research, 8(10), 4877 - 4890. DOI: 10.13189/ujer.2020.081060.

Copyright $\odot 2020$ by authors, all rights reserved. Authors agree that this article remains permanently open access under the terms of the Creative Commons Attribution License 4.0 International License

\begin{abstract}
Second Chance Schools (SCSs) were established in Greece in 1997 in an effort to provide literacy skills to adult school dropouts in order to facilitate their reintegration into society. Science teachers working in SCSs face the challenge of developing scientific literacy-oriented curricula according to the needs of their students. However, empirical data show that most teachers, influenced by their previous classroom experiences in formal education, design theory-laden curricula that aim to introduce SCSs' students to the content of science. This study presents the methodology and results of a two-day constructivist teacher-training workshop which is aimed at changing seven SCSs' science teachers' criteria when selecting and designing topics for their scientific literacy curricula. The analysis and evaluation of the workshop indicated that while science teachers were able to make the critical shift to the selection of topics in line with students' needs (the new topics focused on real-context science-related situations relevant to their students' personal, vocational and social experiences), weaknesses were detected in the science teachers' practices related to the nature of science and the use of scientific knowledge within the context-based issues. The results of this pilot study may be useful to similar teacher training programs that focus on the designing of innovative curricula.
\end{abstract}

Keywords Curriculum Design, Science Teacher Training, Scientific Literacy, Second Chance Schools

\section{Introduction}

\section{The context of Second Chance Schools}

In the 20th century, progress in the fields of science and technology rapidly changed the world we live in. In every decade, the natural, technological and intellectual world which citizens were confronted with presented such sweeping changes that the knowledge and skills people already possessed seemed to be inadequate (Eurydice, 2000). This fact, in conjunction with long-lasting problems such as school leakage, gradually posed a major problem for modern societies: The potential risk of citizens being divided into groups of 'those who know' and 'those who do not know' and, hence, the marginalization of some socially vulnerable populations.

For this reason, in the mid-1990s, the European Commission (EC) issued a report entitled 'White Paper on Education and Training: Teaching and learning Towards the learning society' in which the large number of under-educated, under-trained and unemployed young people in the European community was acknowledged not only as a terrible loss of its most precious resource, i.e. the human resource, but also as a threat to the cohesion of society and to the future of the European model (EC, 1995). Hence, the EC set Lifelong learning as a policy priority for educating European citizens and, towards this end, also proposed the foundation of schools (Second Chance Schools -SCSs-) which would address socially vulnerable populations, though would not resemble 'ghetto schools', but instead would offer individuals a second opportunity to 
adapt to society (EC, 1995).

The pilot project was launched by the EC in 1997, and Athens was one of the 13 cities selected to participate. SCSs in Greece are supervised by the Institute for Continuing Adult Education (IDEKE) - now renamed as the Youth and Lifelong Learning Foundation (INEDIVIM). It comprises a 'two-year, flexible innovative educational program that enables people aged 18 and over who have not completed compulsory education to obtain a certificate equivalent to that of a student graduating from Lower Secondary School' (IDEKE, 2003). The population of students in Greek SCSs consists of those who need special support to cope with the current socio-economic conditions, namely the unemployed, economic immigrants, prisoners, and members of ethnic or religious minority groups. Therefore, the main goal of SCS as set by the IDEKE (2003) is 'to help them [i.e, students] start participating in cultural, political and economic life, and also to enable them to change their status in society'. The key means of accomplishing this is through literacy-driven subject curricula, supplemented by students' participation in interdisciplinary action plans (projects) that are developed by each SCS in collaboration with the local community (IDEKE, 2003). Thus, Greek SCSs seek to reintegrate students into society through the acquisition of the competencies required to act in real life situations. On the other hand, according to the IDEKE, 'it would be wrong to think that technical skills and knowledge have lost their significance. What we need to learn is how to relate and use skills, competencies and knowledge in different social contexts, along with other people' (Chatzitheoharus et al., 2010).

As mentioned above, the target group of Greek SCSs consists mainly - though not exclusively - of adult school dropouts. For this reason, it is important that teachers create a learning environment that will drastically differ from the students' first experience in formal education. This requires teachers to design flexible literacy-based curricula relevant to their student population's specific cultural context and their personal, vocational or social needs and interests, and therefore serve the goal of active and meaningful learning (IDEKE, 2003).

Regarding scientific literacy, IDEKE considers a literate person to be "the one who is capable of participating in the social discourse on scientific and technological issues in a modern society' and, to this end, recommends that science teachers in SCSs design curricula that exploit daily life science-related issues socio-scientific issues (SSI) relevant to students' lives (IDEKE, 2003). The present study focuses on the practices of science teachers in Greek SCSs when they design curricula aiming at reintegrating their students into society through scientific literacy.

\section{The term 'scientific literacy' and the characteristics of scientific literacy curricula}

In an earlier paper (deleted for anonymity), an extended review of the different meanings of the notion of 'scientific literacy' and of the content of the corresponding curricula that have been designed worldwide, been presented. This review found that, despite the fact that scientific literacy is considered by the educational communities as an integral aspect of the culture of citizens of tomorrow and therefore an aim that should be promoted by all contemporary curricula, the 'universal' meaning of the term remains vague in the literature (Durant, 1993; Bybee, 1997). Thus, several interpretations of and approaches to scientific literacy can be traced, based on the views of the curriculum designers and on the needs of each population in question (Laugksch, 2000). Roberts (2007) categorized the approaches of scientific literacy curriculum-designing into two major perspectives/views:

(a) Vision I: (Science literacy) 'gives meaning to scientific literacy by looking at the products and processes of science itself. This approach envisions literacy within science.'

(b) Vision II: (Scientific literacy) 'derives its meaning from the character of situations with a scientific component, situations that students are likely to encounter as citizens. This vision can be called literacy about science-related situations.'

As far as marginalized adult populations are concerned, the corresponding literature (Layton, 1986; Barton, 1998; Roth \& Lee, 2004; Dos Santos, 2009) argues that, due to the differentiated educational goals related to the need of reintegrating these students into society, there is an undeniable necessity to make a transition in curriculum-designing focus from the traditional perspective of science literacy (Vision I) to scientific literacy (Vision II), although this transition by itself does not seem to be sufficient: For these populations, the learning context and its relation with students' experiences play essential roles (Layton, 1986; Roth \& Lee, 2004). However, since most curricula are designed top - down, they disregard a critical parameter of curriculum-designing; namely the students' specific micro-characteristics, interests and needs. Such curricula most commonly address issues of general interest and they focus on the skills, competencies and knowledge not from the perspective of the students, but from that of what modern societies 'demand' for the future citizens (Laugksch, 2000). For instance, Twenty-First Century Science is a curriculum that exploits issues that appear in media articles in order to familiarize students with a form of scientific knowledge that will be implicitly embedded in their daily lives (Millar, 2006), while the so-called Science-Technology-Society (STS) programs bring to light controversial SSI to give prominence to argumentation and decision-making skills essential for future world citizens (Aikenhead, 2003; Ratcliffe 2009; Lee et al., 2013; Van Dijk, 2014; Yacoubian, 2018). Therefore, both above-mentioned approaches possess a macro view of scientific literacy (Laugksch, 2000). On the other hand, curricula in line to the adult scientific literacy literature draw on contexts of 
learning that derive from the individuals' personal, vocational or social lives in the local community. Students are engaged in meaningful collective activities to develop skills and acquire scientific knowledge for participation in community life. The role of community is considered as decisive, according to the corresponding literature, for becoming and belonging, since individuals shape their identities through their communication and collaboration with others (Roth, 2015). This is why participating in community life should be the focal point in an educational process (i.e the means and the main goal of learning), especially for marginalized populations (Roth \& Lee, 2004; Roth, 2015). It should be noted that in such 'authentic', collective endeavours, scientific knowledge is considered to be just one among many forms of knowledge (e.g. politics, economics, everyday know-how, etc.), and thus it cannot be detached from the other forms of knowledge nor from its own specific context, since it derives its existence and meaning through them (Roth \& Lee, 2004).

Radical perspectives which identify the goal of scientific literacy as the need for empowering students to take responsible socio-political action can also be traced in the literature (Barton, 1998; Kolstø, 2001; Levinson, 2006; Dos Santos, 2009). From these perspectives, the corresponding curricula focus on the need for transforming school science education into an endeavour that transcends the boundaries of the school classroom; namely to the commitment to the vision of social reconstruction. The main aim of this so called Critical Scientific Literacy trend is, through value-laden SSI, to enable students to uncover the political interests and social values that lie beneath the scientific and technological practices, thereby empowering them to struggle against the inequitable social reality they live in (Barton, 1998; Kolstø, 2001; Levinson, 2006; Dos Santos, 2009).

Figure 1 attempts to depict the aforementioned trends of the literature in the form of a spectrum, which unfolds from the most traditional point of view (i.e. a focus on the content of science) to the most radical (i.e. a focus on socio-political issues) (deleted for anonymity).

Briefly summarizing the above information from the literature, it is an accepted fact that there is no need to search for a consensus on the meaning of the term scientific literacy and on the appropriate content of a scientific literacy-oriented curriculum (Bybee, 1997). Instead, the term should be conceptualized broadly enough for local school districts and individual classroom teachers to set the goals that are most suitable for their particular situations along with the content that is most appropriate for their students (DeBoer, 2000). Especially as regards marginalized populations (the type of population that SCSs address as well), the proposed approaches exploit science-related situations and activities that draw on or take place in real contexts relevant to the students' personal, vocational and social experiences to support the educational goal of students' participation in community life (Vision II, Micro view).

\section{Spectrum of curriculum designing:}

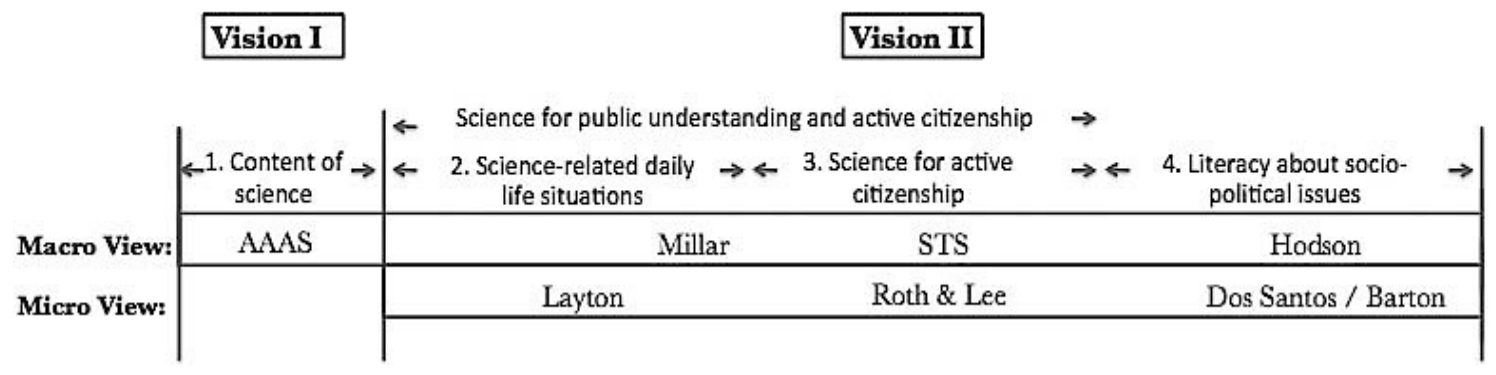

Figure 1. Spectrum of curriculum designing: Emphasis on different aspects of scientific literacy 


\section{Research Problem}

These aforementioned conclusions of the literature that designate the tailoring of the science content to the specific needs of each student population and engaging them in multi-disciplinary activities in the local community that are meaningful to them seems to be aligned with the stated guidelines and philosophy of the Greek SCSs. Thus, in our view, the curricula of SCSs should incorporate some SSI which would provide examples of the social inequalities affecting the students' lives and would thus pave the way for discussions on how struggle is necessary to bring about social equity and justice (Dos Santos and Barton's curriculum exemplars).

However, empirical data in the field of the scientific literacy curricula of Greek SCSs (deleted for anonymity) show that the large portion of the SCSs' science teacher population who are inexperienced in adult education, influenced by their previous classroom experiences in formal education, tend to develop theory-laden curricula (Vision I) and to focus on teaching science topics and phenomena drawing on their own academic backgrounds (e.g. Newtonian laws, the structure of matter). On the other hand, science teachers with previous experience in adult education design curricula aiming at providing daily life, science-related knowledge and skills to facilitate the development of the students' ability to comprehend and cope with everyday issues. However, it should be noted that the majority of these issues deal with situations of general interest, such as earthquakes, the human body, etc. (Vision II, Macro view); none of these are derived from the students' specific life context. Moreover, science teachers in Greek SCSs rarely integrate SSI among those issues they choose to teach; thereby they seem to ignore a crucial aspect of their students' needs, which is their need to reintegrate into community life (deleted for anonymity).

\section{Research Aim and Research Questions}

This study presents an analysis of the results of the methodology used in a training workshop aimed at changing the perceptions and practices of science teachers in Greek SCSs towards scientific literacy curriculum designing. Specifically, the research question consisted of two parts: To what degree can a teacher-training workshop, aiming to motivate SCS science teachers to shift their curriculum-designing behavior to focus on science-related situations relevant to their students' specific needs, influence participants? and Which are the main difficulties science teachers in SCSs face when attempting such a shift?

\section{Research Methodology}

\section{General Background}

As mentioned above, this is a pilot study that focuses on tracing seven Greek SCSs’: (a) perceptions and practices when they design their scientific literacy curricula, (b) their difficulties or potentials when they attempt to shift their practices from theory-laden curricula towards curricula that derive its content from science-related situations relevant to their students' specific needs and experiences. The latter is implemented in the context of a training workshop that adopts a constructivist view of learning and a metacognitive perspective of conceptual change in science teachers' perceptions. The particular characteristics of the framework of this training workshop are analyzed below.

The difficulties involved in developing a teacher training workshop aiming to change science teachers' perceptions and practices

In order to design such a workshop, it is necessary to realize the difficulties traced in similar professional development programs previously attempted, and several such programs reported in the literature were reviewed during the planning process. In most cases, the intended effects of these programs were either not successful or only partly successful (Stolk, De Jong \& Bulte, 2011). This is because a transition from content-based to context-based science curricula (Fig. 2, continuous line) requires a paradigm shift in the science teachers' ideology of teaching (Geddis, 1991), i.e. a shift involving a set of solid and coherent perceptions about science and science education that have been 'constructed' on the basis of their prior teaching experiences (Hewson et al., 1999). More analytically, this shift is related to their views on the nature of scientific knowledge (i.e. a shift from their positivistic perspective towards a socio-cultural perspective that acknowledges the inherent ethical, political, historical aspects of scientific knowledge), on the aims of science education (i.e. a shift from a view that the ultimate educational goal is to train students to acquire basic scientific knowledge towards the goal of teaching about science through issues relevant to the students' interests and needs), and on their own role within the context of the design and delivery of a curriculum (i.e. a shift from the role of a trainer towards to that of a facilitator empowering students' skills for active citizenship) (Lemke, 2001; Bartholomew, Osborne \& Ratcliffe, 2004; Day \& Bryce, 2011).

Moreover, the transition of the science teachers' practices towards the designing of curricula with an emphasis on meeting the needs of a specific group of students (Fig. 2, dashed line) requires the teachers to change their perspective. In other words, each teacher has to both 'step out' of his/her own system of values and perceptions about the importance of scientific knowledge and adapt to the particular context of the learners (namely their culture, interests and needs) in order to assess what is important to be taught from their view (Barton, 1998). This process of adapting to the living conditions of the 
marginalized is not an easy task. It entails, first of all, a certain level of empathy; namely the ability of facing reality 'through the eyes of the students and to confront a world we might not want to confront; a world fraught with inequalities and injustices that shape the students' lives' (Barton, 1998). Secondly, it relates to the teachers' ability to recognize in this reality science-related issues and to exploit them as building blocks for meaningful curriculum-designing for the students.

Another difficulty highlighted in the existing literature is that even when science teachers seem to understand and adopt such context-based innovations relevant to students' lives, they tend to fear that the teaching of science within a context reduces the amount of subject matter, thereby requiring them to both focus in depth on topics they may not know well, and transform and use the content knowledge within these contexts in a way that is meaningful to their students. Thus, they fell that they lack the Pedagogical Content Knowledge (PCK) to teach the authentic science-related issues properly (Stolk, De Jong \& Bulte, 2011; Van Dijk, 2014). Consequently, the main activities of a workshop that aims to facilitate science teachers in SCSs shift in science curriculum-designing should focus on (a) encouraging science teachers' conceptual change through reflection on cognitive conflict, and (b) empowering science teachers' confidence by providing practical guidelines/methods for the educational practice (Pintó, 2005).

\section{Spectrum of curriculum designing:}

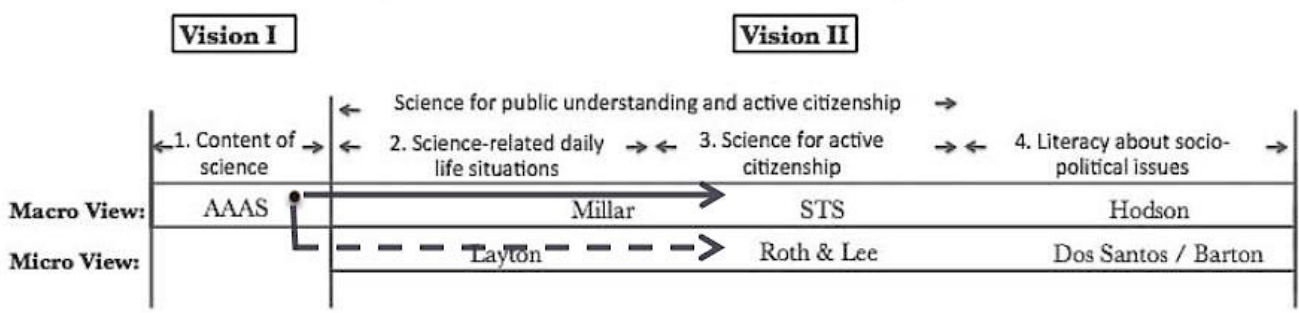

\section{: change in the science teachers' 'ideology of teaching' - - - - - - - : change of perspective for assessing what is important to be taught}

Figure 2. Changes required to make the shift in science teachers' practices on curriculum designing

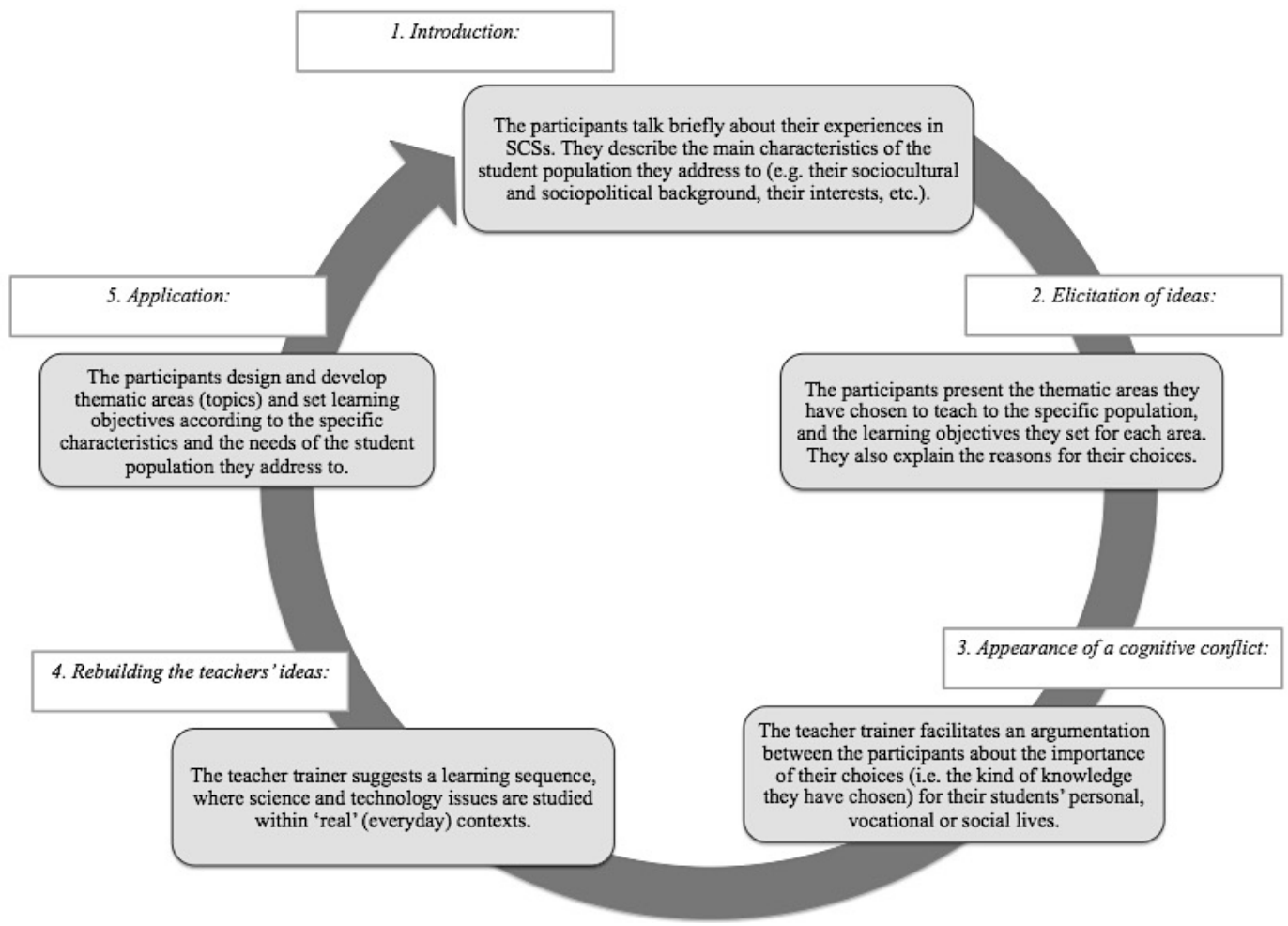

Figure 3. A brief description of the learning cycle applied at the training workshop 


\section{Instruments and Procedures}

Science Teacher Training in an Information Society (STTIS) program provides a methodological framework that relies on the two axes referred to above, i.e. reflection on cognitive conflict and providing practical guidelines for educational practices. The STTIS framework adopts a constructivist view of learning and a metacognitive perspective of conceptual change in science teachers' perceptions. It follows a five-step learning cycle of sequenced phases, starting with identifying the teachers own perceptions and practices in curriculum designing and ending with the design of the desired curriculum (Pintó, 2005). The SCSs' science teacher training workshop implemented in this study is based on this framework (Fig. $3)$.

As shown in Figure 3, the first phase of the workshop (i.e. Introduction) aims to introduce science teachers and the context of the SCS where he/she works to each other. More analytically, each science teacher is encouraged to describe the main characteristics of the student population he/she refers to, namely the students' personal and sociocultural background, their occupations, their interests, the reasons they dropped out of school in the first place, the reasons they returned to school and their intentions and goals relating to this educational procedure.

The second phase (Elicitation of ideas) focuses on tracing the science teachers' perceptions and practices on curriculum designing. To this end, the participants of the workshop are asked to present the goals and the content of the scientific-literacy curriculum they have designed. They describe whether their curriculum is oriented towards the content of science or towards real-life situations, if it incorporates SSI, etc. Moreover, in an attempt to reveal the underlying 'philosophy' of their design, they describe both their rationale for their choices and to the factors they take into account.

In the third phase (Appearance of a cognitive conflict), the teacher trainer attempts to guide the participants to a cognitive conflict by facilitating a group discussion about the importance of scientific knowledge in their students' personal, vocational or social lives. Specifically, relying (a) on the science teachers' perceptions and practices when designing their curricula (as described in phase 2), and (b) on the science teachers' own descriptions of the characteristics of their student population (as described in phase 1), the teacher trainer asks them to consider and discuss the significance of the content knowledge (e.g. Newtonian Laws) for their students' scientific literacy by eliciting responses to questions such as 'Is this knowledge an asset that enriches your students' personal, vocational or social lives and facilitates their integration into society? Why do science teachers frequently include such topics (e.g. Mechanics) in their curricula?'. In this way, the teacher trainer guides the science teachers to a re-definition of the notion of scientific literacy in the specific educational context and of the way it should be approached through the content of a curriculum.

(a) Introduce all topics through some problems or issues meaningful to students' lives. Think about situations that relate to students' personal, vocational and social experiences. scientific knowledge that needs to be learnt.

(b) Help the students to recognize that the problems / issues set depend upon some

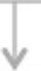

(c) Work back to the underlying science, but only to the extent it is needed to account for the problems / issues set.

(d) Use the underlying science to discuss the nature of scientific knowledge and the interactions between science and society. Stress the fact that scientific knowledge is one of the many resources for decision-making in real life situations.

(e) Return to the initial context (problems / issues set), probing argumentation about possible solutions on the basis of the new knowledge.

Figure 4. An overview of the learning sequence introduced to the science teachers 
Phase 4 (Rebuilding the teachers' ideas) is the intervention stage of the workshop. The teacher trainer provides guidelines (i.e. a five-stage learning sequence for science teachers and an example of the design of a topic which showed step by step how to implement this sequence in practice) relating to the design of context-based topics for SCSs' curricula (Fig. 4).

In the last phase (Application) of the five-step learning cycle, the science teachers had to utilise the principles and guidelines (five-stage learning sequence) introduced during the workshop to design two science topics (i.e. strand units for their curricula) related to their students' experiences and needs; one of the designs was created by teachers working individually, and one by teachers in small groups.

The aforementioned procedure of the workshop was video-recorded and analyzed using content analysis methods with respect to science teachers' difficulties in changing their approach on curriculum designing. Moreover, two science education experts evaluated the topics (strand units) that the science teachers developed in the training workshop with respect to the degree to which key aspects of the training were integrated into the topics.

\section{Sample}

Seven SCSs' science teachers participated in a two-day (12 hours overall) training workshop which aimed to help them to transform the criteria they use when selecting and designing topics (i.e. strand units) for their scientific literacy curricula.

The sample was selected in a way as to ensure that the participants would have a variety of academic backgrounds, different levels of teaching experience in adult and formal secondary education, and would be working with student populations coming from several sociocultural backgrounds and areas of Greece. The characteristics of the sample are summarized in Table 1.

\section{Data Analysis}

As mentioned above, two methods of analysis were used in this research. The first focused on the process of the training workshop, while the second focused on the products of the training workshop.

For the first analysis relating to the process of the workshop was based on methods of content analysis of videotaped lessons/workshops provided in the literature (Bartholomew, Osborne \& Ratcliffe, 2004; Derry et al., 2010; Erickson, 2011). Analytically, the videos were split in episodes, in accordance with the stages of the phases of the training workshop and the tasks given to the science teachers in order to investigate the participants' difficulties or abilities in: (a) arguing for their practices regarding the designing of a curriculum based on their population's needs and characteristics, (b) confronting any inconsistencies emerging in the Phase 3 (Appearance of a cognitive conflict) and (c) making the changes needed in their practices towards their populations' needs and characteristics in the Phase 4 (Rebuilding the teachers' ideas).

As for the analysis of the products of the workshop, two experts in science education evaluated separately the topics developed by the science teachers according to the guidelines proposed in the workshop. Three criteria were used to assess the degree to which teachers had integrated key aspects of the training into the strand units they created: (a) the relevance of the chosen topics to the particular adult population's context of living they were addressed to, (b) the science teachers' ability to transform the scientific knowledge into everyday knowledge relevant to their students' lives, and (c) the science teachers' ability to make interconnections between scientific knowledge and societal issues that give prominence to aspects of the nature of science.

Table 1. The characteristics of the sample

\begin{tabular}{c|c|c|c|c}
\hline $\begin{array}{c}\text { Science } \\
\text { teacher }\end{array}$ & $\begin{array}{c}\text { Sex } \\
\text { (Age) }\end{array}$ & $\begin{array}{c}\text { Academic } \\
\text { background }\end{array}$ & Years of teaching experience & Context \\
\hline S.T. 1 & $\begin{array}{c}\text { Female } \\
(46)\end{array}$ & Physicist & $\begin{array}{c}4 \text { yrs in SCSs } \\
\text { 10 yrs in other adult education contexts }\end{array}$ & SCS in an agricultural area \\
\hline S.T. 2 & $\begin{array}{c}\text { Female } \\
(30)\end{array}$ & Biologist & $\begin{array}{c}2 \text { yrs in SCSs } \\
4 \text { yrs in formal education }\end{array}$ & SCS close to the Greek borders \\
\hline S.T. 3 & $\begin{array}{c}\text { Male } \\
(32)\end{array}$ & Physicist & $\begin{array}{c}3 \text { yrs in SCSs } \\
\text { 3 yrs in other adult education contexts }\end{array}$ & SCS in an agricultural area \\
\hline S.T. 4 & $\begin{array}{c}\text { Male } \\
(60)\end{array}$ & Geologist & $\begin{array}{c}5 \text { yrs in SCSs } \\
\text { yrs in formal education }\end{array}$ & SCS in a prison \\
\hline S.T. 5 & $\begin{array}{c}\text { Male yrs in SCSs } \\
(48)\end{array}$ & Physicist & $\begin{array}{c}45 \text { yrs in formal education } \\
4 \text { yrs in SCSs } \\
4 \text { yrs in formal education }\end{array}$ & SCS on island \\
\hline S.T. 6 & $\begin{array}{c}\text { Female } \\
(33)\end{array}$ & Geologist & No teaching experience & SCS in an agricultural area \\
\hline S.T. 7 & $\begin{array}{c}\text { Female } \\
(26)\end{array}$ & Geologist & & SCS in Athens \\
\hline
\end{tabular}




\section{Research Results}

Science teachers'perceptions and practices before the workshop, as described in Phase 2: Elicitation of ideas

The content analysis of the videotaped workshop revealed that, prior to Phase 4 (Intervention), science teachers' perceptions and practices regarding scientific literacy curriculum designing could be classified into two major categories: (a) curricula aiming to stress the content of science, and (b) curricula aiming at providing familiarity with science-related daily life situations.

Specifically, five out of seven science teachers (S.T. 1, 3, 4, 5 and 7) stated in Phase 2 (Elicitation of ideas) of the workshop that the learning objectives they set and the content they choose are oriented towards the content of science (e.g. Newtonian Laws, the structure of matter, the periodic table and chemical reactions etc.). This is because they identify the term scientific literacy with the process of introducing the students to what they consider as 'the alphabet of science', namely to those concepts, principles, laws, methods, skills, etc. that they (i.e. the science teachers) consider as significant to science itself. Moreover, they argued that the acquisition of this kind of knowledge equips students with essential skills to cope with daily life situations: 'By solving exercises in the context of school science, for example in Mechanics, students build a systematic way of thinking, thus they acquire the skills needed to deal with the problems they usually encounter in their lives'. This perspective, depicts the science teachers' rather simplistic idea that this kind of problem-solving skills can be applied to the complexity of the issues which students confront in real life (Levinson, 2006; Osborne, 2007). In addition, the overall approach of these teachers can be clearly identified as a Vision I approach; hence it disregards the students' own culture, set of interests and needs.

Two science teachers (S.T. 2 and 6), who had only a few years of experience in formal and adult education, designed curricula aiming at providing familiarity with science-related daily life situations. In particular, they stated that the main goal of their curriculum designing was to enable students 'to acquire knowledge useful in daily life and to be able to recall it and use it when necessary'. Their curriculum emphasis was on issues of general interest, such as the construction and function of the human body, the way earthquakes are triggered, the effects of radiation on our lives, the use of chemicals (bases and acids) in daily life, etc. It should be mentioned that in a few cases, teachers have elaborated on topics directly related to their students' personal or vocational experiences (e.g. learning about cancer, for students having a pertinent health issue in their family, or learning about energy, for students working in an energy production plant). While this kind of curriculum designing strongly implies a Vision II approach to scientific literacy and actually provides some interconnection between the curriculum content and the students' specific context of living, it still ignores the aspect of the students' social needs, namely their need for participation in community life and for socio-political commitment to struggle for a change in the structure of society.

Science teachers' difficulties in changing their perceptions and practices during the workshop

The desired shift in science teachers' perceptions and practices regarding scientific literacy curriculum designing (i.e. from theory-laden curricula to context-based curricula related to students' personal, vocational and social experiences) appeared to be more easily realized by the teachers who both already had a few years of teaching experience in SCSs, and had not been acculturated into the ideology of science teaching of the formal education. In contrast, science teachers who had extensive teaching experience in formal education or science teachers who were completely inexperienced in both formal or adult education had great difficulties.

\section{i. $\quad$ Science teachers' extensive teaching experience in formal education as a barrier to making a paradigm shift}

The two science teachers with the most extensive teaching experience in formal education (S.T. 4 and 5) had great difficulties in embracing the idea that scientific literacy is a socially dependent concept, thus, the aims and the content of a science curriculum should be differentiated according to the living environments of the subjects (i.e. the student population) they are addressed to. More analytically, during the argumentation that took place in the workshop Phases 3 and 4 (Appearance of a cognitive conflict and Rebuilding the concepts), these two science teachers heavily defended their choice to develop curricula oriented towards the content of science, and they argued that the scientific knowledge itself is an asset essential for anyone to cope with issues in daily life.

The following dialogue between one of the two science teachers (S.T. 5) and the teacher trainer (T.Tr.) reflects these views:

S.T. 5: My choice to teach concepts or phenomena, such as nuclear fusion or the way free electrons act in metals, may seem to you exaggerated, though, in my opinion, this knowledge is a prerequisite in order to implement daily life phenomena, such as the solar system and the stars, electricity, etc. Such phenomena impress the students, hence they ask about them.

T.Tr.: Why do you think that this kind of knowledge [e.g. the knowledge of the way free electrons act in metals] is important for the specific population's lives? Will it help your students, for instance, to successfully cope with the situations they encounter in their daily lives, such as a short circuit, for example?

S.T. 5: Not necessarily, for sure. Though, isn't the 
knowledge of the way free electrons move in a metal important, by itself? How will the trainee understand what electricity is? I believe that the interpretations involved are significant to everybody.

T.Tr.: Considering the fact that in your annual curriculum program, you develop no more than five strand units, do you believe that a choice such as the subject of the way the free electrons move in a metal is critical to your students' lives, whom most of them work as fishermen?

S.T. 5: As I told you, the interpretations involved are significant. They introduce you to the microcosm, which offers a wide range set of explanations -that are not obvious- to comprehend daily life issues or situations.

Furthermore, even when these two science teachers were involved in an argumentation that seemed to quite convince them that their perspective does not apply to the interests and needs of the SCSs' students, they openly expressed their insecurities as to their ability to apply such a method to their educational practice.

S.T. 4: Even if we accept the value of the proposed approach for the specific educational context [i.e. SCSs], even then I believe that we could not actually implement it effectively in the teaching practice. We have been trained differently, and that affects us. We can't easily detach from the way we've learned to think and teach all these years and start embracing a completely different kind of thinking, suddenly.

As a consequence of their difficulties (i.e. their perspective was inwards science), when S.T. 4 and 5 attempted to choose and develop the subject of their context-based topic in the Application phase (5) of the workshop, they both acted inversely in order to approach the students' context of living: They searched in the content of the topics of their theory-laden curricula (i.e. the curricula they had already developed before the workshop) to find applications of science concepts and phenomena that could possibly be associated with their students' experiences, and then they set these applications as learning contexts for elaborating specific issues relevant to their students (i.e. S.T. 5: 'Atmospheric pressure' => 'Winds' at a SCS on a windy island consisting mainly of fishermen, and S.T. 4: 'Acids and bases' $\Rightarrow>$ 'Antacid medications' at a SCS whose students were serving prison terms, because some of them complained about experiencing stomachaches).

To sum up the situation regarding S.T. 4 and 5, during the course of the workshop, these two science teachers showed great resistance to changing their traditional perceptions and practices. At first, they heavily questioned the proposed method and insisted on teaching the scientific content to their students regardless of their age (adults), special characteristics, needs, living and working conditions, etc. They hold a rigid ideology about science itself (what science is about, i.e. the nature of science) and science education (its goals and the way it should be taught) which is clearly positivistic and simplistic since it presents science as a body of knowledge detached from society, ethics, interests, etc. Their views practically reflect the ideology of the curricula of the secondary formal education, in which they were acculturated. Their extensive experience is limited to implementing a standardised curriculum rather than to designing one.

It should be noted that in Greece, a standardised curriculum is considered to be suitable for all secondary formal education's students (irrespective of an individual's special characteristics and needs), since it virtually aims to train them to pass the University entrance exams rather than to educate them as future citizens. Thus, this type of teaching environment and experience can shape a science teacher's perspective and also hinder one's ability (e.g. S.T. 4 and 5) to design a student-based curriculum for adults. We should point out, however, that besides the objections and difficulties of S.T. 4 and 5, in the end they both really tried to find a way to tailor their practices in order to implement the proposed sequence.

\section{ii. Science teachers' limited teaching experience in formal education as a parameter of adaptability in a new perspective on curriculum-designing}

On the other hand, the four science teachers (S.T. 1, 2, 3 and 6) who had not been acculturated into the ideology of science teaching of the formal system and also had a few years' teaching experience in SCSs, were able to more easily perceive the key features of the training workshop and implement them in their curriculum designing. During workshop Phases 3 and 4 (Appearance of a cognitive conflict and Rebuilding the concepts, respectively), at first, S. T. 2 and 6 tried to support the proposed method when S. T. 4 and 5 questioned it, by recalling examples of their own practices that could facilitate their opponents' change of perspective.

S.T. 6: Something similar to the proposed method I once tried in the classroom by choosing to discuss the subject of prenatal care. I must say that it was the first time that even the most indifferent trainees changed attitude and showed real interest towards my lesson.

S. T. 1 and 3 seemed to hold a passive attitude during this argumentation, yet, when they were asked to choose a topic for their curriculum and to describe their first thoughts on how they intended to develop it, they posed arguments as regards their choices based on their students' specific characteristics and needs. This fact reveals the change in their criteria when selecting the curriculum content.

S. T. 3: The population I refer to mainly consists of farmers. Most of them are looking for new types of crops as they belong to rural cooperatives that want to 
attract subsidies. For this reason, I plan to develop the topic Growing Herbs and interconnect it, on the one hand with various science fields such as Chemistry, Biology, Meteorology, Geology etc., and on the other with the students' sociocultural context. It relates to their professions and to the specific culture of this region [i.e. practical medicine, myths, folk music etc.].

Table 2 presents the topics chosen by the science teachers when they worked individually. As shown, the above-mentioned four science teachers (S.T. 1, 2, 3 and 6) with limited experience in formal education successfully made the desired critical shift from theory-laden curricula to curricula that draws on daily-life, science-related situations relevant to their students' experiences.

Table 2. The topics that science teachers developed individually during the workshop

\begin{tabular}{c|c|c}
\hline $\begin{array}{c}\text { Science } \\
\text { teacher }\end{array}$ & Topic & Context \\
\hline Sc. T. 1 & Olive oil & SCS in an agricultural area \\
\hline Sc. T. 2 & $\begin{array}{c}\text { Immigration, Racism and } \\
\text { Theory of Evolution }\end{array}$ & $\begin{array}{c}\text { SCS close to the Greek } \\
\text { borders }\end{array}$ \\
\hline Sc. T. 3 & Growing Herbs & SCS in an agricultural area \\
\hline Sc. T. 4 & Antacid medications & SCS in a prison \\
\hline Sc. T. 5 & Winds & SCS on a windy island \\
\hline Sc. T. 6 & Maps & SCS in an agricultural area \\
\hline Sc. T. 7 & Landslides & SCS in Athens \\
\hline
\end{tabular}

iii. Science teachers'teaching inexperience as a parameter of insecurity

The most inexperienced science teacher of the workshop (Sc. T. 7) -who had only two months of teaching experience overall- failed to make the intended shift. As a geologist, she chose to teach the topic 'Landslides', despite the fact that she was addressing a student living in Athens. Of course, she recognized the incompatibility of the chosen context to her students' lives, but she also acknowledged her inability to develop a context-based topic that does not rely on the specific field of scientific knowledge which she is familiar with. Characteristically, she stated:

'I have to spend several hours considering issues relevant to my students' lives and interests and ways to utilize them under the guidelines of the proposed method. For the time being, I am not sure if I am able to implement a method that focuses on the context of my students' lives, because such contexts do not rely on the specific subject matter I am familiar with. I believe I have to gain more experience to be able not to be determined by my insecurities that trap me in teaching topics related to my academic background.'

In conclusion, S.T. 7's difficulties are related to her lack of: (a) science content knowledge apart from the area of her specialty (i.e. Geology), and thus she finds it difficult to design trans-disciplined topics, (b) knowledge and competencies to design a science curriculum, and (c) knowledge of how to interconnect science with wider societal issues and how to handle SSI when designing and implementing a context-based topic for her curriculum.

Working groups as a means to overcome science teachers' difficulties in transforming the scientific knowledge into knowledge meaningful to students' lives

When asked to work alone, concerns and weaknesses emerged when the science teachers attempted to transform the scientific knowledge within the chosen context-based issues. Most science teachers had difficulties in determining which science concepts are related to their interdisciplinary topic and to what extent these concepts should be presented. Their inexperience in developing context-based topics (i.e. in transforming the scientific knowledge into daily-life knowledge meaningful for their students) and their insecurity in teaching science outside the 'borders' of their own academic background were inhibiting factors for the science teachers' practices.

However, when the science teachers where asked to work together in small groups to develop another topic, these difficulties seemed to be overcome (Table 3 presents the topics chosen by the science teachers when they worked in small groups.). Often enough, while they were working together to elaborate on their topic, the science teachers focused their discussions on the extent of the transformation that scientific knowledge needs in order to be meaningful to the students. The collaboration of science teachers with different views and academic backgrounds was decisive factor for successfully dealing with this issue.

An example of the science teachers' concerns and how they dealt with them while they were working in groups is illustrated by the following dialogue. The two science teachers (S.T. 3 and 6), in this case, try to develop a topic about Wine and alcohol since they both address students in SCSs in agricultural areas.

S.T. 3: To what extent do you think that we should elaborate on the concept of alcohol? Shall we refer to its molecular formula?

S.T. 6: No. I believe that this knowledge is not useful to our students' lives.

S.T. 3: Yes, but subsequently, when we refer to the process of converting grapes into wine, shouldn't we mention the reaction of the alcoholic fermentation?

S.T. 6: No. In my opinion, we just need to explain that this process is related to the role of a yeast that appears when we crush the grapes.

Table 3. The topics that science teachers developed in small groups during the workshop

\begin{tabular}{c|c|c}
\hline Science teacher(s) & Topic & Context \\
\hline S.T. 1, 2 \& 7 & $\begin{array}{c}\text { Sexually Transmitted } \\
\text { Diseases }\end{array}$ & $\begin{array}{c}\text { SCSs in deprived } \\
\text { areas }\end{array}$ \\
\hline S.T. $3 \& 6$ & Wine and alcohol & $\begin{array}{c}\text { SCSs in agricultural } \\
\text { areas }\end{array}$ \\
\hline S.T. $4 \& 5$ & Space technologies & $\begin{array}{c}\text { SCS in prison and } \\
\text { SCS on an island }\end{array}$ \\
\hline
\end{tabular}




\section{The products of the workshop}

As mentioned above the products of the workshop (i.e. the strand units designed by the science teachers) were analyzed by two science education experts regarding: (a) the relevance of the chosen topics to the particular adult students' context of living, (b) the science teachers' ability to transform the scientific knowledge into everyday knowledge relevant to their students' lives, and (c) the science teachers' ability to make interconnections between scientific knowledge and societal issues that give prominence to aspects of the nature of science. Following are details of the analysis.

(a) The relevance of the chosen topics to the particular adult students' context of living

According to the experts, the participants were able to make the critical shift from curricula oriented towards the content of science to context-based topics related to the students' everyday lives, needs and experiences ('Landslides' and 'Space technologies' are obviously the two exceptions, though these choices depict the science teachers attempt to make a shift from Vision I to a Vision II - Macro view approach to curriculum designing). As shown above, in tables 2 and 3, the science teachers seem to perceive and more readily draw on the vocational and personal lives of the learners in their attempt to design context-based curricula; thus their curricula have similarities with Layton's (1986) and Roth and Lee's (2004) curriculum exemplars. In only a few cases the topics that science teachers chose derived from the social experiences of the students ('Immigration, Racism and Theory of Evolution' and to some extent 'Sexually Transmitted Diseases'). However, radical perspectives for curriculum designing that stress socio-political issues related to the specific social and cultural context of their students (the Dos Santos approach) are totally excluded. The teachers' inability to approach the social contexts of their students' lives and to interconnect the living conditions and problems of the individuals with the broader, systemic problems of society possibly relates to the teachers' own cultural and ideological backgrounds (Barton, 1998).

(b) The science teachers'ability to transform the scientific knowledge into everyday knowledge relevant to their students'lives

Difficulties were traced in the way science teachers used scientific knowledge within the contexts of the topics they designed. According to the experts, in most cases the science teachers successfully managed to transform the scientific knowledge into everyday knowledge relevant to their students' lives. Though, in the cases where the everyday life problems/issues set required a range of scientific knowledge beyond the science teachers' specific academic field of knowledge (e.g. olive oil; a topic developed by a physicist), it seemed as if the science teachers were unsure/insecure about how to handle and present the relevant scientific knowledge. Thus, in these cases, they tended to teach science concepts in a more abstract way. The results were significantly better when the science teachers worked in small groups: The content knowledge was more targeted and transformed in such a way that it seemed to be directly relevant to the students' interests and needs. This finding is consistent with the findings of the qualitative analysis of the workshop.

(c) The science teachers' ability to make interconnections between scientific knowledge and societal issues that give prominence to aspects of the nature of science

The analysis showed that most topics (seven out of ten), irrespective of whether they had originated from the personal, vocational or social 'identities' of the students, did effectively incorporate some interconnections between science and societal issues related to the lives of the students in SCSs. Through these issues, the science teachers aimed at triggering the students' critical thinking and positioning as an effort to facilitate their reintegration into society, which was one of the goals of the workshop (an example of such an attempt is shown in Figure 5). However, according to the science experts, the discussions raised about aspects of the nature of scientific knowledge were weak, indicating that the science teachers would benefit from further training in this area.

\section{An example of topics designed by the science teachers}

Figure 5 presents the development of a characteristic example of the topics that the science teachers chose to design during the workshop ('Sexually Transmitted Diseases'). The example depicts that, regardless of the detected difficulties and weaknesses, the science teachers tried (and to a certain extent managed) to tailor their practices in accordance with their students' needs and experiences. 
(a) Sexually Transmitted Diseases (STDs). Presentation of a media report that refers to prostitutes' responsibilities for the transmission of AIDS to clients, many of whom were married men with families.

(b) Key questions: What is AIDS; What are STDs? Do you know other STDs besides AIDS? How are they transmitted? Are there any particular population groups 'at risk', or population groups who are responsible for the transmission of such viruses (e.g. prostitutes, homosexuals)?

(c) Elicitation of students' ideas about the transmission of STDs and HIV. Discussion on how viruses infect the human body and how the human immune system reacts. Visit of an expert (Venereologist): Information on the mode of transmission of STDs as an effort to tackle students' prejudices. Symptoms of STDs. Prevention or treatment?

(d) Highlighting the role of science in the field of prevention, diagnosis and treatment of STDs. Discussion about social phenomena, such as why in the public debate the prostitutes were exposed and mocked while the customers were protected. The role of mass media in the reproduction of social stereotypes. The role of scientific knowledge as an asset for not being manipulated.

(e) Back to the initial context and discussion on the adoption of responsible sexual behavior.

Figure 5. An example of the development of the science teachers' topics within the workshop

\section{Discussions}

As regards socially vulnerable adult populations, the overview of the literature presented above relating to scientific literacy curricula highlights the importance of context-based learning in relation to the students' personal, vocational or social experiences. Furthermore, drawing attention to meaningful socio-political issues plays a crucial role in promoting students' critical thinking skills and in empowering citizens to struggle for the reconstruction of society.

To this end, this study reports on a pilot workshop that has been designed and implemented with an aim to change Greek SCSs' science teachers' perceptions and practices towards science curriculum-designing. The analysis showed that the science teachers' showed resistance in changing their views even when they were convinced about the inconsistencies of their practices. Though, the discussions and collaboration between science teachers having different qualifications (i.e. years of experience, academic background, competencies, ideology of teaching etc.) proved to be a key feature of the training workshop. Finally, the training workshop could be characterized as effective (considering the workshops' duration) in developing most science teachers': (a) perceptions about the way to transform scientific knowledge into SCS knowledge (as shown in the dialogues when they worked in groups at the phase of the Application), and (b) practices in selecting and designing topics (strand units) for their scientific-literacy curricula compatible with the specific characteristics of their students (as shown in Table $2 \& 3$ ).

However, in order to facilitate educators that either have no teaching experience at all or, on the contrary, have extensive teaching experience in formal education, it seems that the main activities of the workshop should be adjusted to meet the specific needs of these teachers. Moreover, further training seems to be needed to develop science teachers' PCK (a) on the teaching of authentic science-related context-based issues, and (b) on the nature of scientific knowledge (Van Dijk, 2014).

\section{Conclusions and Implications}

In conclusion, this paper articulated the perceptions and practices of seven Greek SCSs' science teachers when 
designing curricula that aim to achieve the goal of reintegrating their adult students in society through scientific literacy. Moreover, it brought out their difficulties or potentials when they attempt to shift their practices, within the context of a constructivist teacher-training workshop, from theory-laden curricula towards context-based scientific literacy curricula related to their students' needs and experiences. Science teachers' prior teaching experience in formal education designated as a decisive parameter in order to make such a paradigm shift. On the other hand, the collaboration within the training workshop of science teachers that hold different views and had academic backgrounds facilitated their effort to put at the heart of the debate their students' experiences and needs at the process of the design.

The research-based knowledge resulting from this workshop, especially the ones related to the means of overcoming the science teachers' difficulties in transforming the scientific knowledge into knowledge meaningful to students' lives, may prove useful as to designers of similar teacher training programs as to the the Greek Institute for Continuing Adult Education itself. Though, this study should be considered as a pilot since it represented the difficulties and potentials of only seven SCSs' science teachers, who worked with student populations that came from several sociocultural backgrounds. Thus, further and wider research is needed in this still less inquired, whilst sensitive field, since it is crucial to help the SCSs' science teachers towards the designing of such innovative, scientific literary curricula developed to cultivate the adult students' critical thinking and to empower their ability to face daily-life issues that they confront in their personal, professional or social life.

\section{REFERENCES}

[1] Aikenhead, G. (2003). STS Education: A Rose by Any Other Name. In Cross R. (Eds) A Vision for Science Education: Responding to the Work of Peter J. Fensham, 59-75, London, Routledge, 2003.

[2] Bartholomew, H., Osborne, J., \& Ratcliffe, M. (2004). Teaching students 'ideas-about-science': Five dimensions of effective practice. Science Education, 88(5), 655-682. https://doi.org/10.1002/sce.10136

[3] Barton, A. C. (1998). Teaching science with homeless children: Pedagogy, representation, and identity. Journal of Research in Science Teaching, 35(4), 379-394. https://doi.org/10.1002/(SICI)1098-2736(199804)35:4\%3C 379::AID-TEA8\%3E3.0.CO;2-N

[4] Bybee, R. W. (1997). Toward an Understanding of Scientific Literacy. In: Graeber, W. \& Bolte, C. (eds.), Scientific Literacy - An international Symposium, Kiel:IPN.

[5] Chatzitheocharous, P., Nicolopoulou, V., \& Giovanni, H. (2010). Introduction to adult education. Educational material for the training of SCSs' teachers. Athens: IDEKE Publications (in Greek).

[6] Day, S. P., \& Bryce, T. G. K. (2011). Does the discussion of socio-scientific issues require a paradigm shift in science teachers' thinking? International Journal of Science Education, 33(12), 1675-1702. https://doi.org/10.1080/095 00693.2010.519804

[7] De Boer, D. E. (2000). Scientific literacy: Another look at its historical and contemporary meanings and its relationship to science education reform. Journal of Research in Science Teaching, 37, 582-601. https://doi.org/10.1002/1098-2736( 200008)37:6\%3C582::AID-TEA5\%3E3.0.CO;2-L

[8] Derry, S. J., Pea, R. D., Barron, B., Engle, R. A., Erickson, F., Goldman, R., Hall, R., Koschmann, T., Lemke, J. L., Sherin, M. G., \& Sherin, B. L. (2010). Conducting Video Research in the Learning Sciences: Guidance on Selection, Analysis, Technology, and Ethics. Journal of the Learning Sciences, 19(1), 3-53. https://doi.org/10.1080/10508400903452884

[9] Dos Santos, W. L. P. (2009). Scientific literacy: A Freirean perspective as a radical view of humanistic science education. Science Education, 93, 361-382.https://doi.org/1 0.1002/sce.20301

[10] Durant, J., Evans, G., Thomas, G. (1993) Public understanding of science in Britain: The role of medicine in the popular representation of science. Public Understanding of Science, 1, 161-182. http://citeseerx.ist.psu.edu/viewdoc/ download?doi=10.1.1.884.9956\&rep=rep1\&type=pdf

[11] Erickson, F. (2011). Uses of video in social research: a brief history. International Journal of Social Research Methodology, 14(3), 179-189. https://doi.org/10.1080/1364 5579.2011.563615

[12] European Commission (2001), Second chance schools: Results of a European pilot project, Brussels. https://ec.europa.eu/budget/euprojects/second-chance-schoo len

[13] European Commission (1995). White paper on education and training - Teaching and learning - Towards the learning society. Office for official publications of the European Communities.

https://op.europa.eu/en/publication-detail/-/publication/d0a 8aa7a-5311-4eee-904c-98fa541108d8

[14] Eurydice (2000). Results of the Eurydice survey: Lifelong learning: The contribution of educational systems. http://hdl.voced.edu.au/10707/113251

[15] Geddis, A. N. (1991). Improving the quality of science classroom discourse on controversial issues. Science Education, 75(2), 169 - 183. https://doi.org/10.1002/sce.37 30750203

[16] Hewson, P. W., Tabachnick, B. R., Zeichner, K. M., Blomker, K. B., Meyer, H., Lembeger, J., Marion, R., Park, H., \& Toolin, R. (1999). Educating prospective teachers of biology: Introduction and research methods. Science Education, 83(3), 247 - 273. https://doi.org/10.1002/(SICI) 1098-237X(199905)83:3\%3C247::AID-SCE1\%3E3.0.CO; 2-C

[17] IDEKE (2003). School guidelines for Second Chance Schools. Athens: IDEKE Publications (in Greek).

[18] Kolstø, S. D., (2001). Scientific literacy for citizenship: 
Tools for dealing with the science dimensions of controversial socioscientific issues. Science Education, 85(3), 291-310. https://doi.org/10.1002/sce.1011

[19] Laugksch, R. (2000). Scientific literacy: A conceptual overview. Science Education, 84, 71-94. https://doi.org/10. 1002/(SICI)1098-237X(200001)84:1\%3C71::AID-SCE6\% 3E3.0.CO;2-C

[20] Layton, D., Davey, A., \& Jenkins, E. (1986). Science for specific social purposes (SSSP): Perspectives on adult scientific literacy. Studies in Science Education, 13, 27-52. https://doi.org/10.1080/03057268608559929

[21] Lee, H., Yoo, J., Choi, K., Kim, S.-W., Krajcik, J., Herman, B., \& Zeidler D. (2013). Socioscientific issues as a vehicle for promoting character and values for global citizens. International Journal of Science Education, 35, 2079-2113. https://doi.org/10.1080/09500693.2012.749546

[22] Lemke, J. L. (2001). Articulating communities: Sociocultural perspectives on science education. Journal of Research in Science Teaching, 38(3), 296-316. https://doi.org/10.1002/1098-2736(200103)38:3\%3C296::A ID-TEA1007\%3E3.0.CO;2-R

[23] Levinson, R. (2006). Towards a theoretical framework for teaching controversial socio-scientific issues. International Journal of Science Education, 28, 1201-1224. https://doi.org/10.1080/09500690600560753

[24] Millar, R. (2006). Twenty first century science: Insights from the design and implementation of a scientific literacy approach in school science. International Journal of Science Education, 28, 1499-1521. https://doi.org/10.1080/0950069 0600718344

[25] Osborne, J. (2007). Science education for the twenty first century. Eurasia Journal of Mathematics, Science \& Technology Education, 3, 173-184. https://doi.org/10.12973 /ejmste/75396

[26] Pintó, R. (2005). Introducing curriculum innovations in science: Identifying teachers' transformations and the design of related teacher education. Science Education, 89(1), 1-12. https://doi.org/10.1002/sce.20039

[27] Ratcliffe, M. (2009). The place of socio-scientific issues in citizenship education. In: Ross A (ed), Human Rights and Citizenship Education, 12-16. London: CiCe.

[28] Roberts, D. A. (2007). Scientific literacy/science literacy. In: Abell SK \& Lederman NG (ed), Handbook of research on science education, 729-780. New Jersey: Lawrence Erlbaum Inc.

[29] Roth, W.-M. (2015). Becoming and belonging: From identity to experiences as developmental category in science teaching. In. L. Avraamidou (Ed.) Identity in science teaching, 295-320.

[30] Roth, W.-M., \& Lee, S. (2004). Science education as/for participation in the community. Science Education, 88, 263-291. https://doi.org/10.1002/sce.10113

[31] Stolk, M. J., De Jong, O., \& Bulte, A. (2011). Exploring a framework for professional development in curriculum innovation: Empowering teachers for designing context-based chemistry education. Research in Science Education, 41, 369-388. https://doi.org/10.1007/s11165-01 0-9170-9

[32] Van Dijk, E. M. (2014). Understanding the heterogeneous nature of science: A comprehensive notion of PCK for scientific literacy. Science Education, 98, 397-411. https://doi.org/10.1002/sce.21110

[33] Yacoubian, H. A. (2018). Scientific literacy for democratic decision-making. International Journal of Science Education, 40(3), 308-327. https://doi.org/10.1080/0950069 3.2017.1420266 